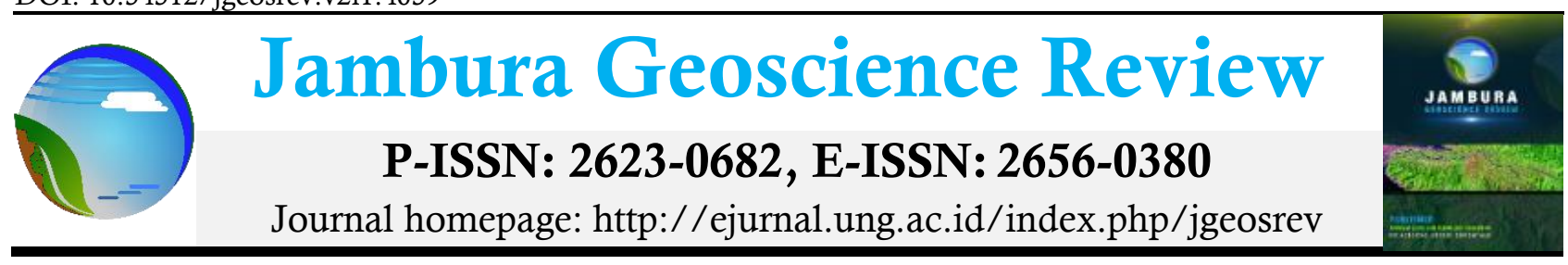

\title{
STUDI MORFOLOGI PANTAI REWATA'A DESA LALAMPANUA
}

\author{
Rusdi $^{\mathrm{a}}$, Feri Padli ${ }^{\mathrm{a}}$, Hendra $^{\mathrm{b}}$ \\ a Prodi Pendidikan IPS, Fakultas Ilmu Sosial, Universitas Negeri Makassar, Jl AP. Pettarani, Kota Makassar, 90222, \\ Indonesia \\ ${ }^{b}$ Jurusan Ilmu dan Teknologi Kebumian, Fakultas MIPA, Universitas Negeri Gorontalo, Jl Jendral Sudirman, Kota \\ Gorontalo, 96128, Indonesia
}

\section{ARTICLE INFO}

\section{Article history:}

Received: 5 December 2019

Accepted: 23 December 2019

Available Online: 10 July 2020

\section{Keywords:}

Cliffed Coast; Igneous Rock;

Morphology; Sediment

\section{Corresponding author:}

Rusdi

Universitas Negeri Makassar, Makassar,

Indonesia

Email: rusdi@unm.ac.id

\begin{abstract}
This research is aimed at knowing morphology characteristics and factors which influence landform that is located at Rewata'a Coastal. Geomorphology is a study stressed on landform characteristics with all processes and material at the world surface. The landform is seen as the appearance of landform as the main aspect of the landscape. The method used in this research is a qualitative descriptive method by collecting primary data, such as images or photos of land from that is directly taken from the research location. The phenomenological approach used to explain what, where, how, and why related to landform which based on available theory and prior research. The research result concludes that the Rewata'a Village morphology is cliffed coast, namely the coastal with the vertical cliff. Composed by host rock or hard sediment. Although we can find sand land at bay and north area. The landform found are delta, sea cave, beach, spit, notch, cliff, wave-cut platform, and stack.
\end{abstract}

Copyright (C) 2020 JGEOSREV-UNG This open access article is distributed under a Creative Commons Attribution (CC-BY) 4.0 International license

\section{Pendahuluan}

Indonesia adalah daerah tropis dengan pulau atau kepulauan yang merupakan ciri khas dari negara kepulauan. Departemen Dalam Negeri mengungkapkan bahwa Indonesia memiliki 17.500 pulau. Sebagai negara kepulauan, Indonesia memiliki garis pantai sepanjang $81.000 \mathrm{~km}$. Garis pantai yang berada pada urutan kedua terpanjang di dunia (Marfai et al., 2015). Hal tersebut dipengaruhi oleh jumlah pulau yang sangat banyak. Sumber daya potensial yang dimiliki karena berada pada wilayah yang sangat unik sebagai ekosistem yaitu daerah peralihan antara laut dan darat. Kesejahteraan masyarakat pesisir menjadi hal yang perlu diperhatikan, bukan hanya itu, kepedulian terhadap lingkungan dan pembangunan berkelanjutan sustainable development menjadi hal yang sangat fundamental (Dartoyo, 2004). Diluar dari harapan tersebut, kepedulian ini masih sangat terbatas dalam aspek morfologinya. Meskipun hal tersebut merupakan aspek mendasar yang harus diperhatikan karena morfologi membahas tentang pembentukan fitur-fitur alami (bentuk-bentuk daratan), prosesproses yang bekerja padanya, dan perubahan-perubahan yang terjadi. Pulau Sulawesi disusun oleh berbagai formasi batuan yang meliputi batuan beku, sedimen, hingga batuan metamorf (Eksan et al., 2019). Geologi pesisir berkaitan dengan formasi batuan dan struktur yang terlihat di tebing dan singkapan pantai, dan sedimen yang telah diendapkan di wilayah pesisir (Bird, 2008; Solihuddin, 2011; Dewandaru \& Saputro, 2014; Nofirman, 2017).

Pantai Rewata'a merupakan bagian dari Provinsi Sulawesi Barat. Jalur sesar naik yang memiliki arah sesar utara-selatan yang mempengaruhi wilayah ini, hal tersebut ditandai dengan sungai-sungai yang menuju arah selatan. Pada bagian barat terdapat rifting, sebagai akibat dari penipisan pada kerak benua, hal inilah yang mengakibatkan pada selat makassar terdapat system blok (Arnott \& Davidson, 
2010). Di sebelah barat Pantai Rewata'a terdapat Palung Makassar dengan kedalaman mencapai 2.300 m. Akibat mekarnya lantai dasar laut Palung Makassar menyebabkan terjadinya zona subduksi kecil yang menunjang ke arah timur (Rusdi \& Marfai, 2014). Sehingga ditemukan beberapa blok antara Teluk Mamuju dan Mandar terangkat dan blok pegunungan yang bentuknya menggulung-gulung. Terban walanae berada pada bagian tengahnya, terban ini memanjang dari utara-selatan yang berisikan sedimen vulkanik kuarter. Dari tinjauan aspek morfogenesa bentuklahan pantai Rewata'a sangat unik, sebagai bentukan dari adanya tenaga tektonik sebagai pembentuknya. Pengelolaan pantai untuk pengembangan ke depan, tentunya dibutuhkan data atau informasi yang dibutuhkan sebagai dasar sebelum melakukan pengembangan pantai. Aspek fisik merupakan hal paling utama yang menjadi fokus dalam mengenali karakteristik pesisir. Tujuan penelitian ini adalah untuk menganalisis jenis bentuklahan pantai sebagai pedoman dalam penentuan pengembangan suatu wilayah pesisir untuk masa yang akan datang.

\section{Metode}

\subsection{Jenis penelitian}

Jenis penelitian yaitu basic research yang bertujuan untuk memperluas/memperdalam teori dan memperoleh data empiris yang dapat digunakan untuk memformulasi teori (Tika, 2005). Metode yang digunakan dalam penelitian ini adalah metode deskriptif kualitatif dengan menggunakan pendekatan survei dan interpretasi data geospasial untuk menemukan dan mendeskripsikan morfologi Pantai Rewata'a.

\subsection{Lokasi penelitian}

Lokasi penelitian merupakan wilayah dalam obyek penelitian. Terletak pada koordinat $3^{\circ} 28^{\prime} 19^{\prime \prime}$ LS - 329' 17" LS dan 118 52'19" BT - 118 53'46" BT (Gambar 1). Secara administrasi berada di Pantai Rewata'a di Desa Lalampanua Kecamatan Pamboang Kabupaten Majene.

\subsection{Alat dan bahan}

Adapun alat yang digunakan dalam penelitian meliputi: Global Positioning System (GPS); untuk menentukan posisi gejala bentuklahan, klinometer; digunakan untuk mengukur kemiringan lereng,

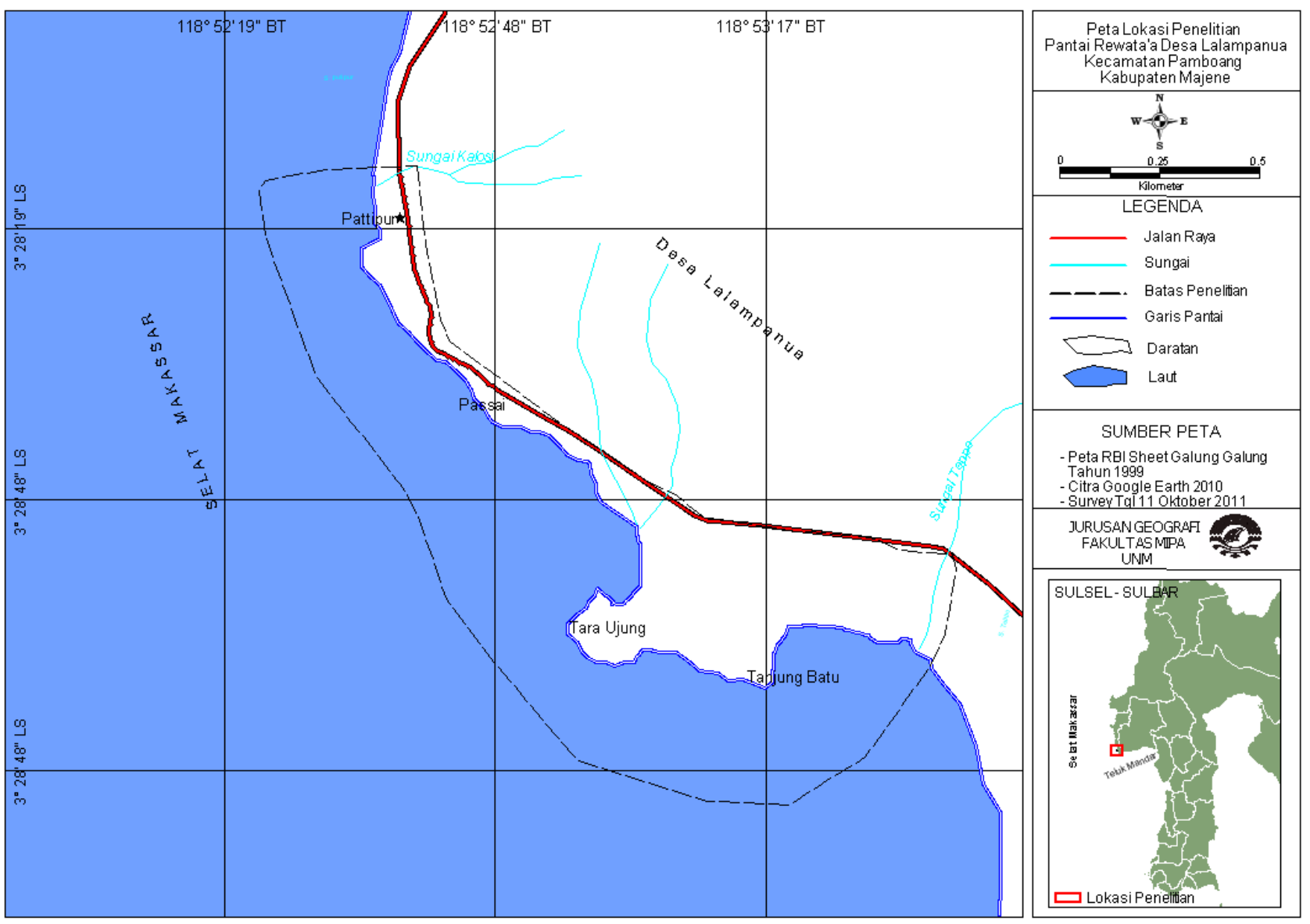

Gambar 1. Peta lokasi penelitian 
kompas geologi; untuk mengukur kemiringan (dip) dan jurus (strike) pelapisan batuan, roll meter; digunakan untuk mengukur jarak antar titik di lapangan, kompas bidik; menentukan arah, palu geologi; digunakan untuk mengambil sampel batuan, perangkat lunak Sistem Informasi Geografi (SIG), dan Kamera; untuk merekam objek pengamatan. Selain itu, bahan yang digunakan meliputi: citra DEM ASTER, peta geologi skala 1: 250.000, peta lereng skala 1: 300.000, peta penggunaan lahan 1: 300.000 .

\subsection{Data penelitian}

Data primer diperoleh melalui pengukuran lapangan. Data primer yang diperlukan meliputi: (1) Data Morfogenesis, data ini berupa hasil pengukuran, pengamatan dan hasil analisis tentang proses/asalusul terbentuknya suatu bentukan lahan di lapangan. (2) Data Morfografi, berupa kenampakan khas yang ada pada suatu bentuklahan dilihat dari bentuk, model dan ciri-ciri kenampakan suatu fenomena bentang lahan (Noor, 2011; Munir 2003).

Tabel 1. Karakteristik morfologi Pantai Rewata'a

\begin{tabular}{|c|c|c|c|}
\hline Titik pengamatan & Material & $\begin{array}{l}\text { Kemiringan } \\
\text { lereng }\end{array}$ & Keterangan \\
\hline $\begin{array}{l}\text { Muara sungai } \\
\text { Kalosi (118 } 52^{\prime} \\
39.79^{\prime} \text { BT dan } 03^{\circ} \\
08^{\prime} 12^{\prime \prime} \text { LS) }\end{array}$ & $\begin{array}{l}\text { Gisik dengan material pasir putih, } \\
\text { puing-puing karang, bahan- bahan } \\
\text { organik dari sungai. }\end{array}$ & $10^{\circ}$ & \\
\hline $\begin{array}{l}\text { Bukit Pattipur } \\
\left(3^{\circ} 28^{\prime} 12.77^{\prime \prime} \mathrm{LS}\right. \\
\text { dan } 118^{\circ} 52^{\prime} 39.43^{\prime \prime} \\
\text { BT) }\end{array}$ & Cliff dengan material batuan beku & $45^{\circ}$ & \\
\hline
\end{tabular}

\section{LS dan \\ $\left.118^{\circ} 52^{\prime} 44.80^{\prime \prime} \mathrm{BT}\right)$}

Tara Ujung $\left(3^{\circ} 29^{\prime}\right.$

$1.80^{\prime \prime} \mathrm{LS}$ dan $118^{\circ}$

53 ' 2.70"BT)

Tanjung Batu $\left(3^{\circ}\right.$

29' 6.33" LS dan

$118^{\circ} 53^{\prime} 21.21 " \mathrm{BT}$ ) batuan cadas, warnanya hitam

pekat dan kompak.

Gisik dengan material penyusun

dari kumpulan karang mati, pasir,

lumpur dan lumpur

Cliff dan stack dengan material

batuan beku.

Cliff dan notch dengan material batuan gamping

Gisik dengan material penyusun

Muara Sungai

Teppo

(118 53'36.50" BT

dan $3^{\circ} 29^{\prime} 3.50 " L S$ ) dari pasir dan bahan-bahan organik

dari sungai

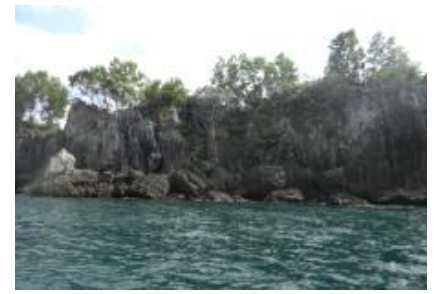

$90^{\circ}$

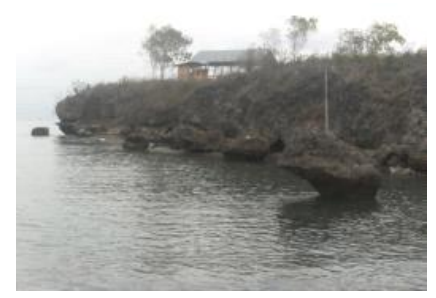

$85^{\circ}$

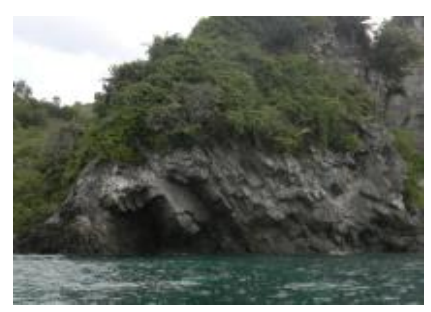

$10^{\circ}$

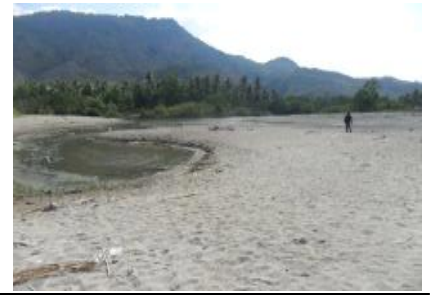


Data sekunder diperoleh dari pengumpulan literatur, penelitian terdahulu dan pengumpulan bahan yang dijadikan sebagai informasi mengenai data yang akan dianalisis. Data sekunder yang diperlukan berupa hasil-hasil penelitian dari para peneliti sebelumnya yang dipadukan dengan kajian pustaka dan teori yang ada, untuk menganalisis data primer. Data ini diantaranya berupa data litologi daerah pantai, morfologi, morfometri, dan bentuklahan pantai.

\subsection{Variabel penelitian}

Variabel merupakan segala sesuatu yang menjadi objek dalam suatu penelitian. Variabel secara sederhana diartikan sebagai ciri individu, gejala objek peristiwa yang diukur dan dihitung secara kuantitatif. Hasi 1 pengukuran suatu variabel, bisa konstan dan bisa pula berubah-ubah (Mulyanto, 2010). Adapun yang menjadi variabel geomorfologi pesisir (Gunawan \& Santosa, 2005) dalam penelitian ini yaitu: (1) morfologi pantai meliputi bentuk pantai, lereng, bentuk lereng, topografi, dan relief. (2) material pantai meliputi jenis batuan dan pasir.

\section{Hasil dan Pembahasan}

\subsection{Karakteristik morfologi Pantai Rewata'a}

Hasil penelitian morfologi pantai Rewata'a memiliki perbedaan karakteristik morfologi. Materialmaterial penyusun yang beragam pada setiap titik pengamatan (Tabel 1) .

\subsection{Bentuklahan destruksional}

\subsubsection{Cliff}

Cliff merupakan bentuk lereng terjal yang berada di pantai menyerupai dinding (Bird, 2008). Bentuk Cliff yang tampak pada Gambar 2 terdapat di Passai tepatnya $3^{\circ} 28^{\prime} 31.80^{\prime \prime}$ LS dan 118 52'44.80"BT merupakan bentuk hasil kikisan gelombang yang relatif lambat dengan batuan dasarnya terdiri dari beku berwarna gelap, juga dapat ditemukan notch dan lereng yang cekung ke arah daratan overhanging (menggantung). Kemiringannya mencapai $45^{\circ}$ dengan ketinggian 10 mdpl. Bentukan lereng yang overhanging akan memberi gaya berat dari batuan diatasnya yang akan meninggalkan bentuk cliff yang vertical. Di dasar cliff sudah tampak wave cut platform yang bisa mengurangi kekuatan hempasan gelombang.

Bentuklahan destruksional yang berada di Pantai Rewata'a tersebar dibeberapa bagian, Cliff dapat ditemukan di Pattipur, Passai, Tara Ujung, dan Tanjung Batu. Cliff yang berada di Pattipur memiliki

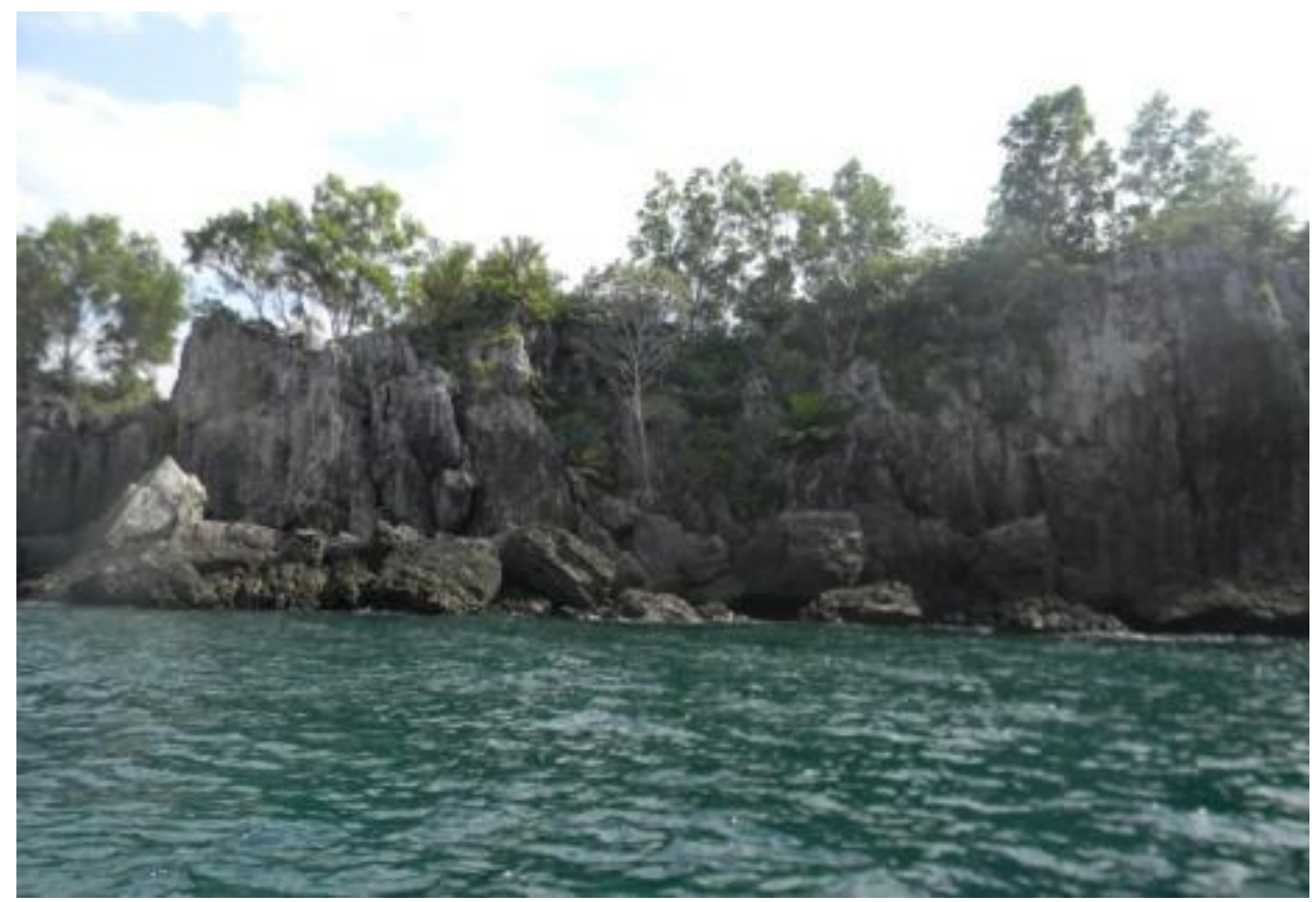

Gambar 2. Cliff yang tampak dari arah utara 
karakteristik yang mudah terkikis karena material penyusunnya masih di dominasi dengan lapisan tanah walaupun batuannya terdiri dari batuan beku, namun dengan adanya karang sebagai pelataran pantai yang berada di depannya sebagai pemecah gelombang sehingga energi gelombang yang sampai pada dinding cliff berkurang. Selain itu, di Pattipur masih ada cliff yang memiliki karakteristik yang batuan penyusunnya berlapis-lapis, sehingga tampak adanya retakan. Dengan cirinya yang banyak retakan hal itu mempermudah aksi gelombang melakukan pengikisan. Pada celah batuan gelombang terkonsetrasi yang lama kelamaan menjadi lubang dan ketika tidak mampu lagi menahan beban yang ada diatasnya maka batuan tersebut jatuh meninggalkan lubang besar yang bentuknya memanjang seperti tumpukan kayu kemudian jatuh terbagi dalam ukuran besar, sedang, sampai ukuran kerikil. Itu bisa dibuktikan dengan melihat material yang ada di bawah tebing. Selain aktivitas gelombang faktor yang bekerja pada pengikisan ini adalah iklim dan curah hujan yang bisa melapukkan batuan tersebut. Dengan melihat warna batuan bagian atasnya lebih nampak terang dibandingkan bagian bawah. Bagian batuan yang selalu tergenang air ditumbuhi tiram, organisme ini juga salah satu faktor untuk mempercepat pengikisan.

Titik pengamatan Passai cliff tersusun dari batuan beku yang berwarna gelap, dengan cirinya yang kompak proses pengikisan yang terjadi sangat lambat dan pada dasar cliff ini air tidak pernah kering, daerahnya selalu tergenang air, sehingga pada bagian batuan yang merupakan konsentrasi gelombang akan membentuk notch. Walaupun pengikisannya lambat apabila terjadi pengikisan, pengikisannya berupa bongkahan sehingga tampak jelas daerah yang hilang. Hal tersebut biasanya terjadi pada musim barat dimana kekuatan gelombangnya sangat kuat.

Titik pengamatan Tara Ujung karakteristik cliff yang dindingnya sangat terjal dan memanjang, di depan cliff sudah terdapat wave cut platform, dan bongkahan batu yang besar. Sehingga pengikisan yang terjadi tidak terlalu nampak karena adanya penghalang aksi kekuatan gelombang. Di dasar cliff selalu tergenangi air sehingga tidak tampak lagi adanya pengangkutan atau beachdrif sedimen. Sedimen yang berada di Tara Ujung diangkut gelombang kembali ke laut.

Titik pengamatan Tanjung Batu cliff tersusun dari batu gamping, di sepanjang Tanjung batu merupakan cliff dengan karakteristik batuannya banyak lubang-lubang kecil yang bisa mempercepat pengikisan selain itu batu gamping mudah larut, sehingga sangat mudah terbentuk notch bahkan bisa membentuk sea cave. Di dasar cliff terdapat banyak bongkahan-bongkahan batuan merupakan hasil runtuhan.

\subsubsection{Notch}

Notch hampir sama dengan cliff, yang membedakan antara keduanya terletak pada bagian tebingnya yang langsung dengan permukaan air laut dan memiliki lengkungan kearah darat sehingga dapat kita lihat bentuk relung pada tebing (Bird, 2008), di sepanjang Tanjung Batu ditemukan notch dengan panjang 135 meter, kedalamannya sekitar $1.3 \mathrm{~m}$ (Gambar 3).

Bentuklahan notch di pantai Rewata'a dapat ditemukan di sub bagiannya yaitu di Passai, Tara Ujung dan Tanjung Batu. Notch yang berada di Passai berada pada cliff yang memiliki susunan batuan beku yang kompak. Sehingga bentuk notchnya masih merupakan bentukan awal. Titik pengamatan Tara Ujung notchnya tidak terlalu tampak karena selalu tergenang dengan air, hanya bisa ditemukan di dasar cliff pada saat air laut mengalami surut. Sedangkan di Tanjung Batu dapat ditemukan notch di sepanjang cliff, bentuknya yang memanjang ke samping. Hal tersebut terjadi karena di Tanjung batu batuan penyusunnya dari batuan gamping sehingga sangat mudah gelombang mengikis dasar cliff.

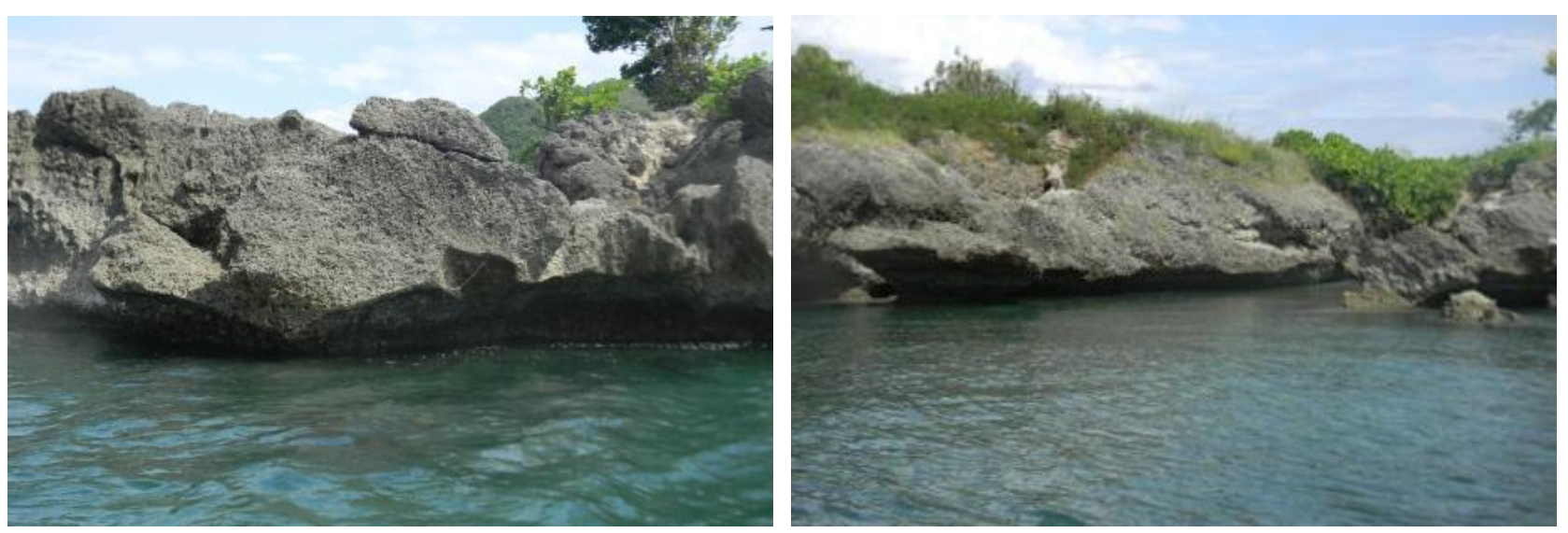

Gambar 3. Notch di sepanjang Tanjung Batu 

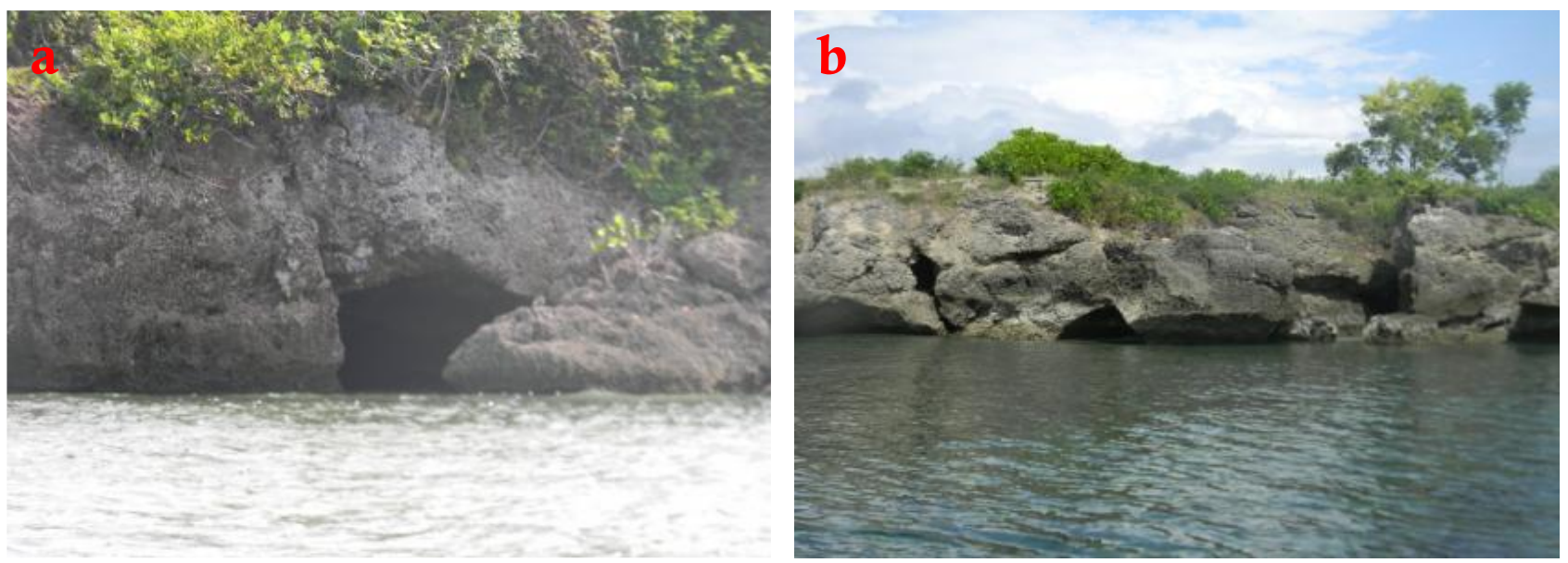

Gambar 4. (a) Sea cave kedalaman $100 \mathrm{~cm}$. (b) Sea cave kedalaman $50 \mathrm{~cm}$

\subsubsection{Sea cave}

Sea cave merupakan sebuah lubang yang dibentuk oleh kekuatan gelombang atau lebih dikenal dengan nama gua laut (Nuriyanto et al., 2018). Di Pattipur tepatnya $3^{\circ} 28^{\prime} 26.53^{\prime \prime}$ LS dan $118^{\circ} 52^{\prime} 43.51^{\prime \prime}$ BT ditemukan sea cave yang merupakan tingkat awal pembentukan sea cave. Batuan dasarnya merupakan batuan beku dengan diameternya $20 \mathrm{~cm}$, kedalamannya sekitar $15 \mathrm{~cm}$. Di sepanjang Tanjung Batu tepatnya $3^{\circ} 29^{\prime} 5.00^{\prime \prime} L S$ dan $118^{\circ} 53^{\prime} 20.03^{\prime \prime B T}$ ditemukan sea cave dengan diameternya 90 $\mathrm{cm}$ dengan kedalaman $1 \mathrm{~m}$ (Gambar 4a). Selain itu, ditemukan beberapa sea cave dengan diameter 30 $\mathrm{cm}$ dengan kedalaman $50 \mathrm{~cm}$ (Gambar 4b).

Sea cave yang berada di Pattipur bentuk penyusunnya dari batuan berlapis-lapis sehingga bentuk mulutnya segilima, terlihat patahan-patahan batuan yang kasar di dasar sea cave. Selanjutnya Sea Cave ditemukan di Tanjung Batu, materialnya dari batu gamping bentuk mulutnya yang bulat. Di ujung tanjung batu ditemukan 7 sea cave, walaupun mulutnya belum terlalu besar.

\subsection{Bentuklahan hasil sisa}

\subsubsection{Stack dan stump}

Stack merupakan bentuk pilar raksasa (tugu) yang berada di pantai (Shofian et al., 2019). Proses terbentuknya merupakan bentuk lanjutan dari notch dan cliff yang memiliki tingkat resistensi batuannya menahan aksi gelombang. Sebuah stack yang telah direduksi menjadi pilar pendek dikenal sebagai stump. Stump yang terdapat di Pattipur memiliki tinggi $1.7 \mathrm{~m}$ dan lebarnya $2 \mathrm{~m}$.

Titik pengamatan pantai Passai ditemukan stack (Gambar 5) yang tampak seperti tower di daerah karst, berupa komplek perbukitan yang puncak-puncaknya menonjol, namun antara bukit yang satu dengan bukit lainnya masih terlihat berhubungan. Panjang perbukitan stack yaitu $67 \mathrm{~m}$ warnanya gelap tampak telah mengalami proses pelapukan.

Secara umum stack dan stump dapat ditemukan di Pattipur, Passai, Tara Ujung, dan Teppo. Stump di Pattipur reliefnya halus dan bentuknya bulat, di Passai ditemukan stump yang ditengahnya telah nampak retakan, di Tara Ujung bentuk stacknya yang memanjang, menyebar di depan cliff, reliefnya sangat kasar, bagian atasnya runcing, setiap pinggiran stack sudah mengalami retakan, di sekitar stack
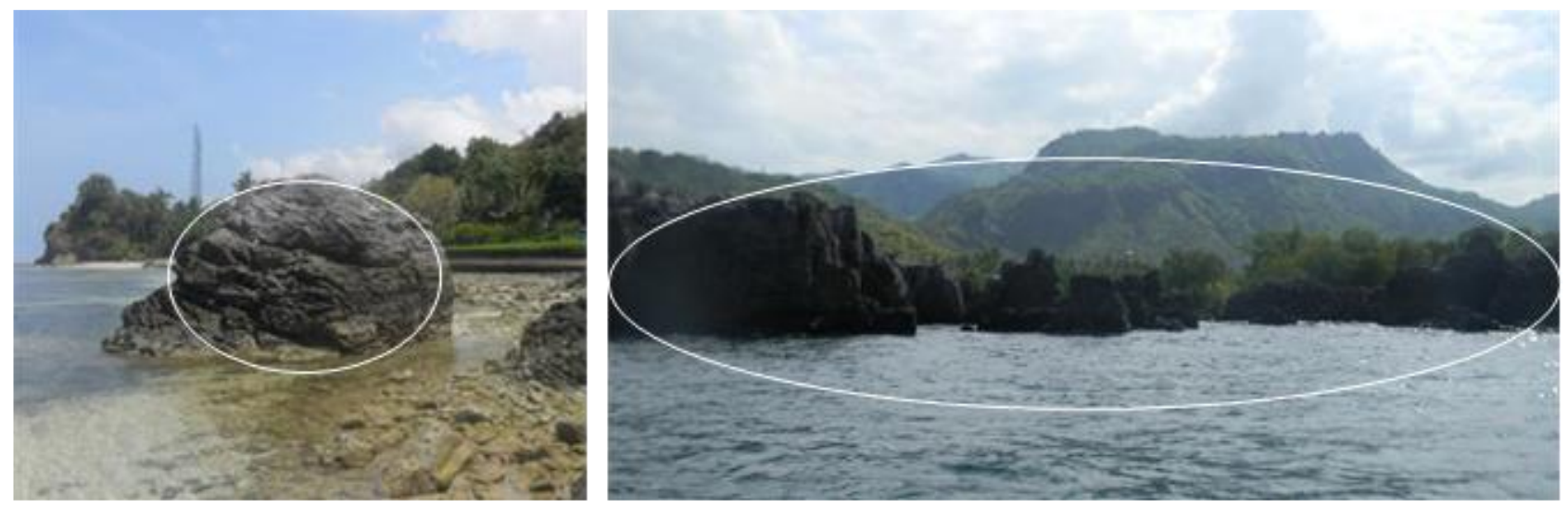

Gambar 5. Stack dan stump 


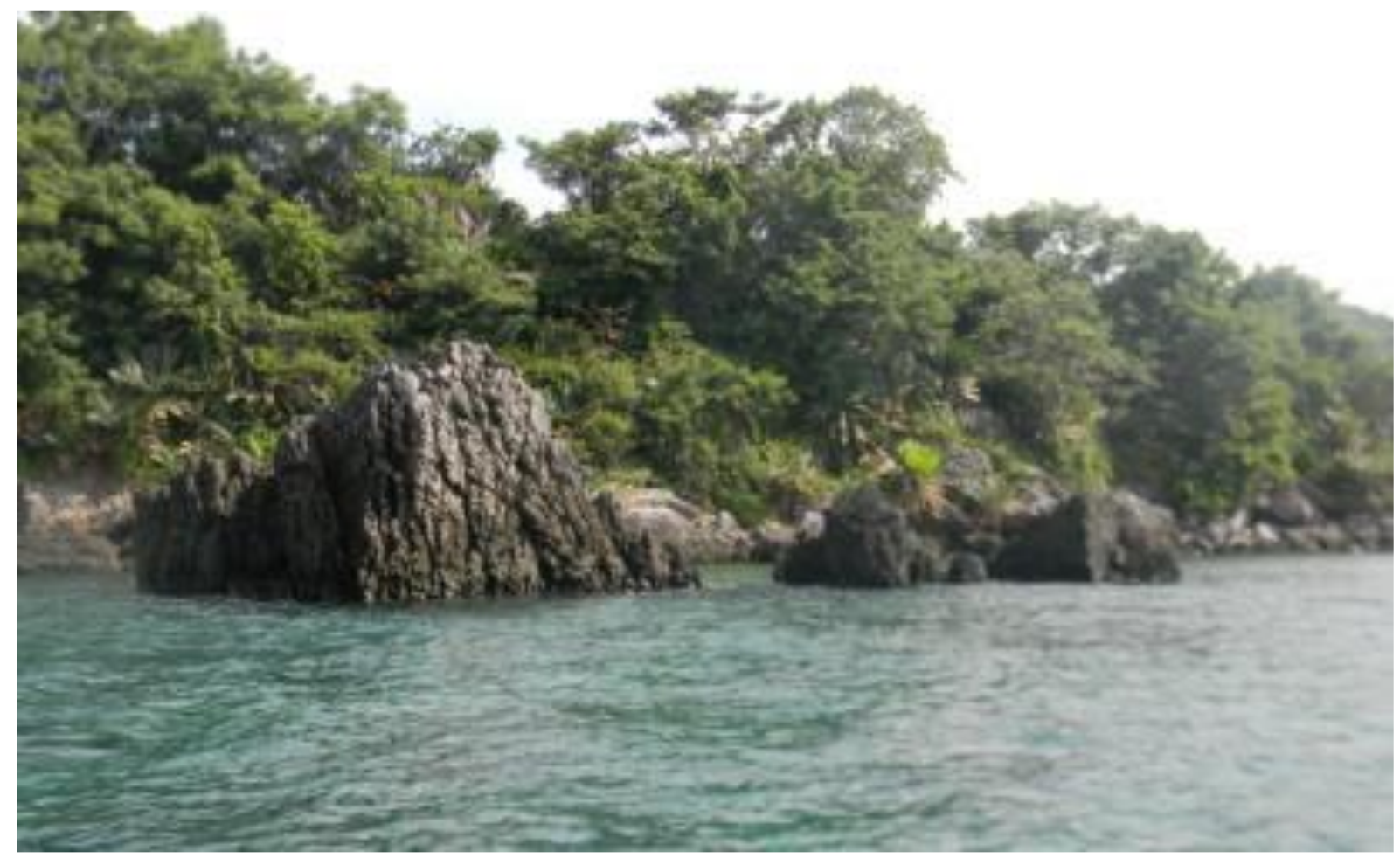

Gambar 6. Stump

terlihat bongkahan-bongkahan hasil pengikisan. Di Teluk Teppo terdapat satu stump yang berdiri sendiri, bagian dasarnya telah tipis akibat kikisan gelombang sedangkan pada bagian atasnya masih tebal (Gambar 6).

\subsection{Bentuklahan konstruksional}

Zona endapan yaitu zona dimana terkumpulnya hasil pengikisan, bentuk-bentuk hasil pengikisian ini berupa pecahan, dan mineral, atau material yang mengalami pergerakan dari berbagai sumber, kemudian terendapkan oleh air dan material. Bentukan yang menonjol di tepi pantai termasuk bagian dari pengendapan tersebut, yang terbentuk dari larutan kimia berupa material yang melayang dalam air (Huda et al., 2019). Zona endapan ini pada umumnya ada pada bagian pantai yang kekuatan gelombangnya melemah dan daerah dekat dengan muara sungai.

\subsubsection{Gisik}

Muara sungai Kalosi tepatnya arah gelombang yang menghempas tepi pantai kemudian arus mengangkut hasil material (Gambar 7). Material yang di bawah berupa material hasil kikisan yang berupa pasir (Gambar 8), material kikisan batuan beku, batu karang dan material sungai. Pengangkutan material sangat ditentukan oleh arah pergerakan arus dan gelombang. Material tersebut diendapkan ketika gelombang telah mencapai titik lemahnya. Selanjutnya gisik pada Tanjung Batu materialnya
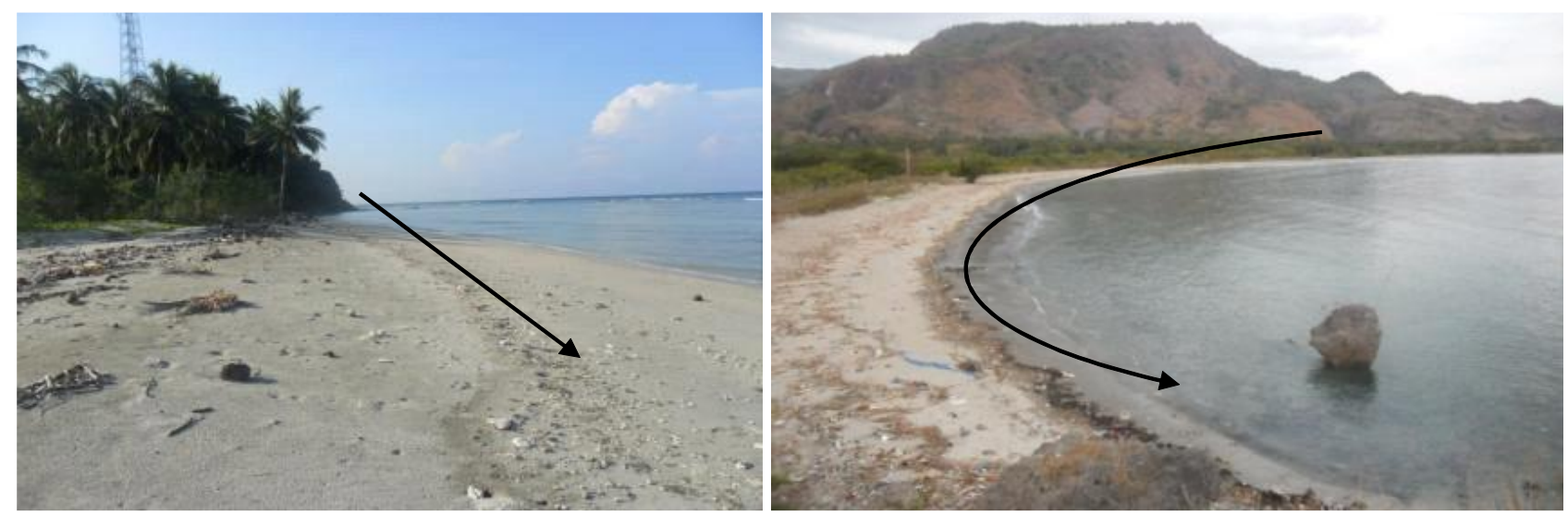

Gambar 7. Gelombang yang membentur tepi pantai selanjutnya material tersebut diangkut dan diendapkan ke arah samping sesuai arah arus susur pantai 


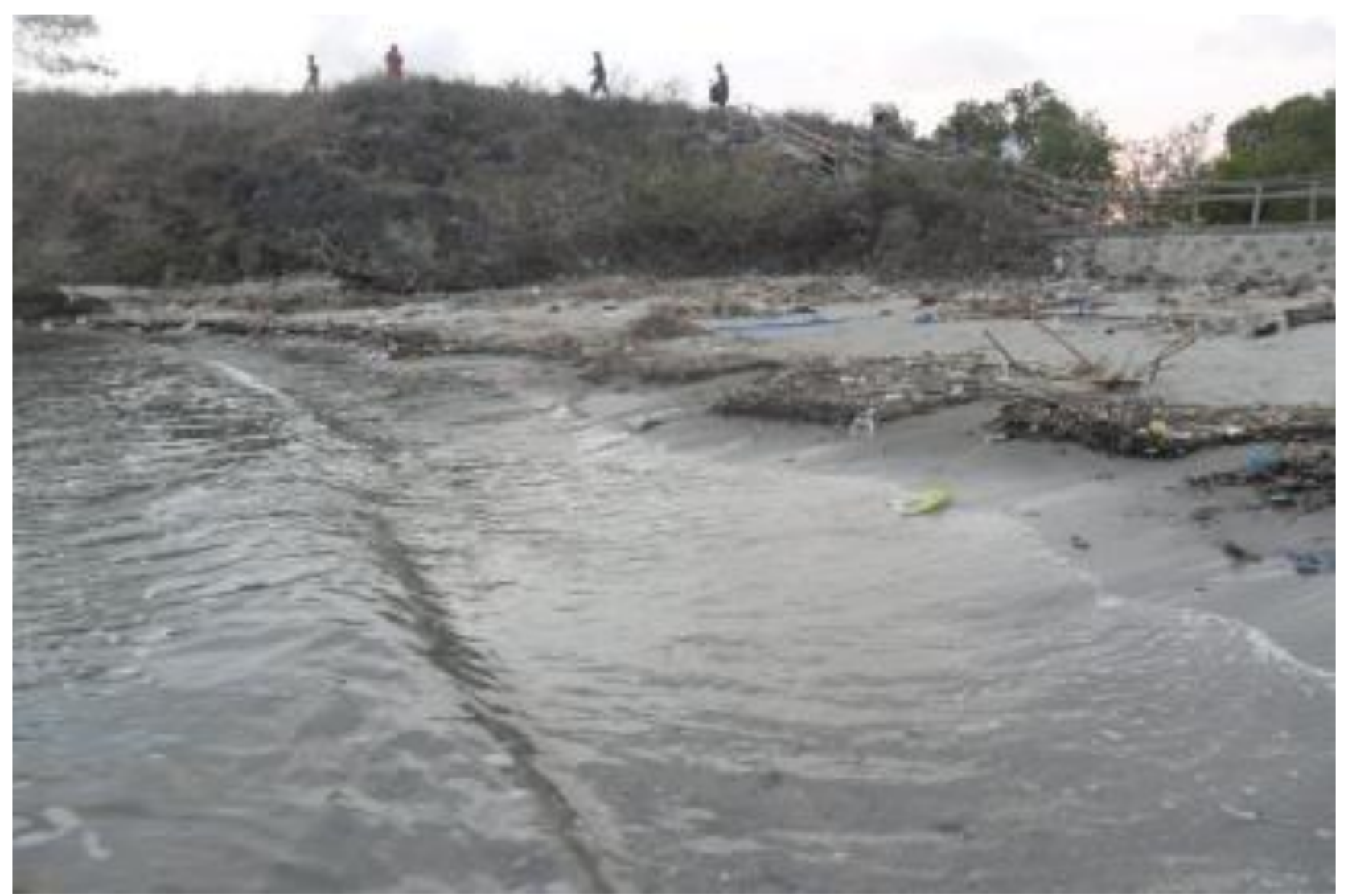

Gambar 8. Kondisi swash saat membentur tepi pantai dan backswash selanjutnya diendapkan oleh arus

berbatuan gamping berkembang di sekitar lekukan-lekukan Tanjung Batu dimana sedimen yang bergerak di sepanjang pantai terjebak, material gisik merupakan hasil erosi air laut pada daerah cliff dan masswating yang jatuh dari atas Tanjung Batu. Hal dibuktikan dengan melihat bongkahan-bongkahan batuan gamping yang tidak mungkin terbawa oleh gelombang air laut. Selain itu gisik juga disusun oleh koral yang berkumpul di tepi Tanjung Batu (Gambar 9).

Di Teluk Teppo dapat didapatkan gisik yang tersusun dari bermacam-macam partikel organik dan nonorganik. Selain material dari hasil abrasi batuan gamping materialnya juga berasal dari pasir. Profil bentuk gisik ditentukan oleh ukuran, bentuk, dan komposisi penyusunnya, julang pasang surut dan sifat gelombang yang datang. Karena penyusunnya terdiri dari pasir halus dan pasir kasar maka sudut kemiringannya ada yang rendah dan lebih besar.

\subsubsection{Delta}

Delta sungai adalah bentuklahan yang terbentuk dari pengendapan sedimen yang terbawa oleh sungai ketika aliran meninggalkan mulutnya dan memasuki aliran air yang lebih lambat atau stagnan (Bird, 2008). Delta bisa ditemukan di Muara Sungai Kalosi tepatnya $3^{\circ} 28^{\prime} 15.2112$ "LS dan $118^{\circ} 52^{\prime}$
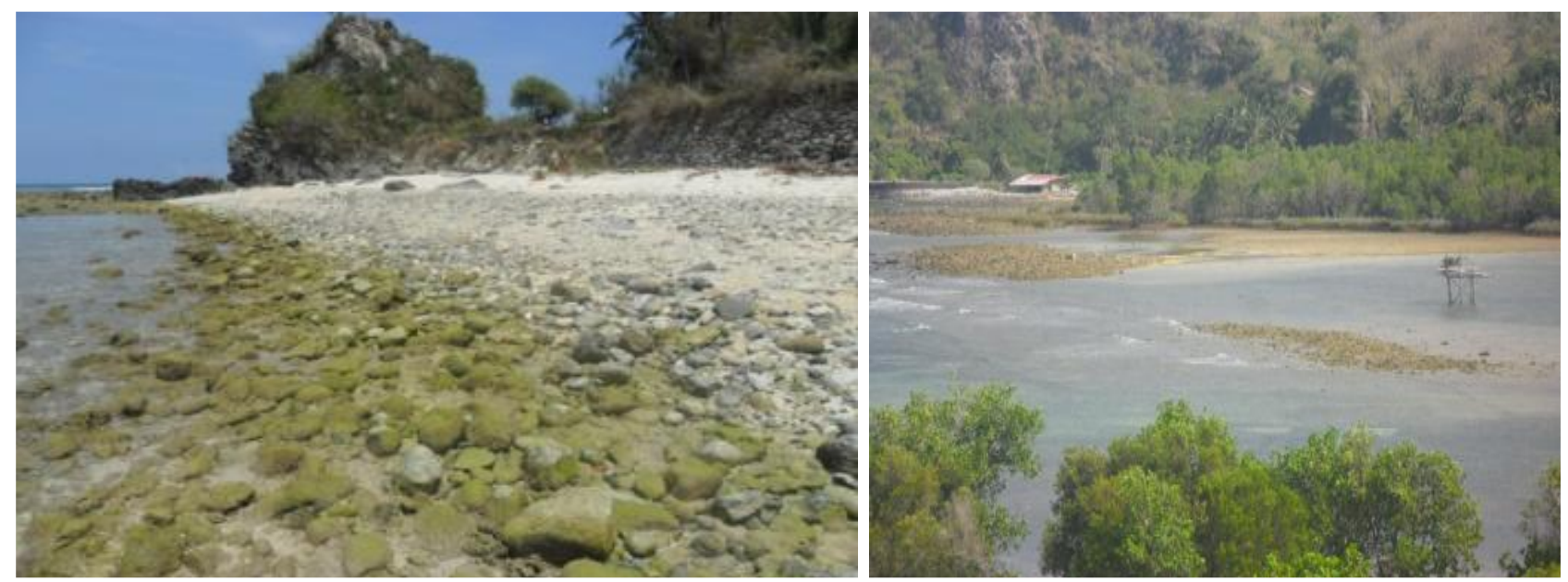

Gambar 9. Batu karang yang membentuk endapan 

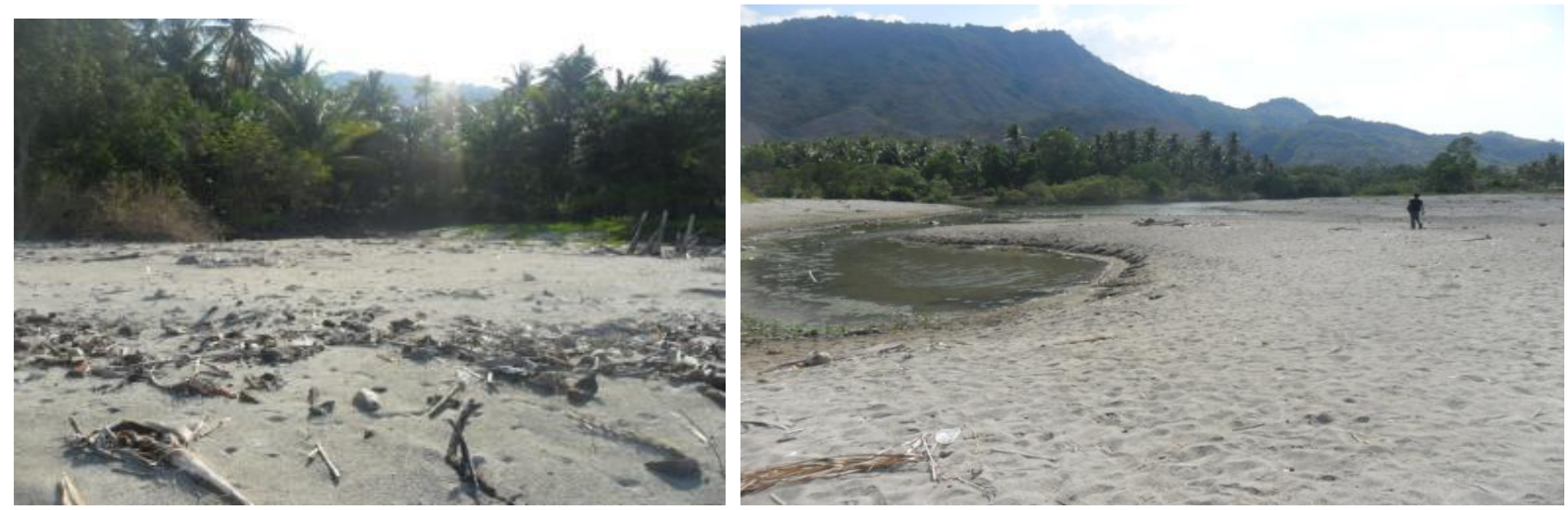

Gambar 10. Delta sungai Kalosi dan Teppo

34.65"BT dengan material pasir yang berwarna putih, berupa sampah-sampah seperti kelapa, plastik. Sedangkan delta yang terdapat di Sungai Teppo deltanya lebih luas dibandingkan dengan di muara sungai Kalosi. Delta di Sungai Teppo bentuknya memanjang dan melengkung dari arah laut ke muara sungai Teppo. Pada musim kemarau material yang di bawa dari sungai Teppo tertampung pada delta (Gambar 10), sehingga air sungai tidak bisa masuk ke laut lewat muara tetapi air sungai tembus ke laut melalui lapisan aquifer (Gambar 10). sedangkan pada musim hujan air sungai sudah bisa menembus delta, karena pada musim hujan debit air sungai bertambah besar. Proses terbentuknya delta sangat dipengaruhi aliran air dari hulu sungai dan pasang surut air laut yang masuk kedalamnya, serta pasokan sedimen, tetapi tidak seluruhnya sedimen primer dari hulu (Sampurno, 2007). Sedimen dengan butiran besar akan mengendap pada saat memasuki laut pasang surut karena makin mengecilnya kecepatan aliran di dalamnya sedangkan sedimen layang yang terkandung di dalam aliran debit akan menggumpal menjadi bebutir yang lebih besar, pada waktu aliran memasuki ruas bagian hilir (Sarbidi, 2007).

\subsubsection{Endapan hasil organisme}

Bentuklahan organisme yaitu bentuklahan yang dibentuk oleh binatang termasuk manusia (Craghan, 2003). Endapan yang terdapat di Passai merupakan hasil kerja manusia terdiri dari material batuan beku yang berwarna cerah dan bentuknya bundar. Berdasarkan hasil interpretasi, endapan tersebut bukan hasil alami dari bentukan gelombang, karena kekuatan gelombang tidak bisa mengangkut material seperti itu, dominan materialnya tidak sama dengan hasil erosi yang berada disampingnya, tidak adanya bekas longsoran lereng yang berada disekitarnya. Bentuknya yang bulat mencirikan hasil erosi batuan yang mengalami proses panjang dan jauh biasanya terdapat di sungai. Menurut hasil wawancara endapan tersebut merupakan hasil sisa bahan yang digunakan untuk pembangunan talude sebagai pondasi jalan (Gambar 11). Endapan tersebut selain oleh aktifitas manusia juga berlangsung secara alami. Selain itu, adanya material-material angkutan gelombang yang terkonsentrasi pada daerah tersebut, terdapat juga material yang jatuh dari bukit.

Terumbu karang terjadi akibat proses organik dan relatif lambat yang memungkinkan adanya keterlibatan manusia dalam proses terbentuknya. Karang yang telah berada di atas permukaan laut,
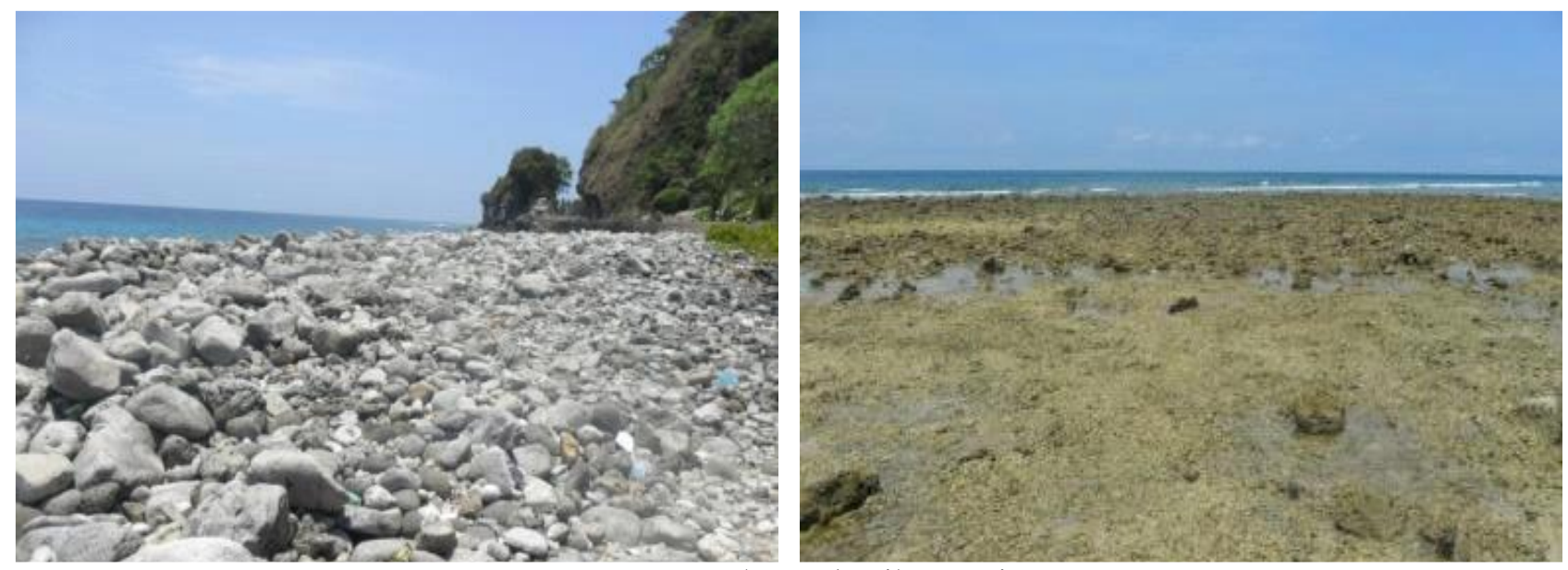

Gambar 11. Endapan hasil organisme 


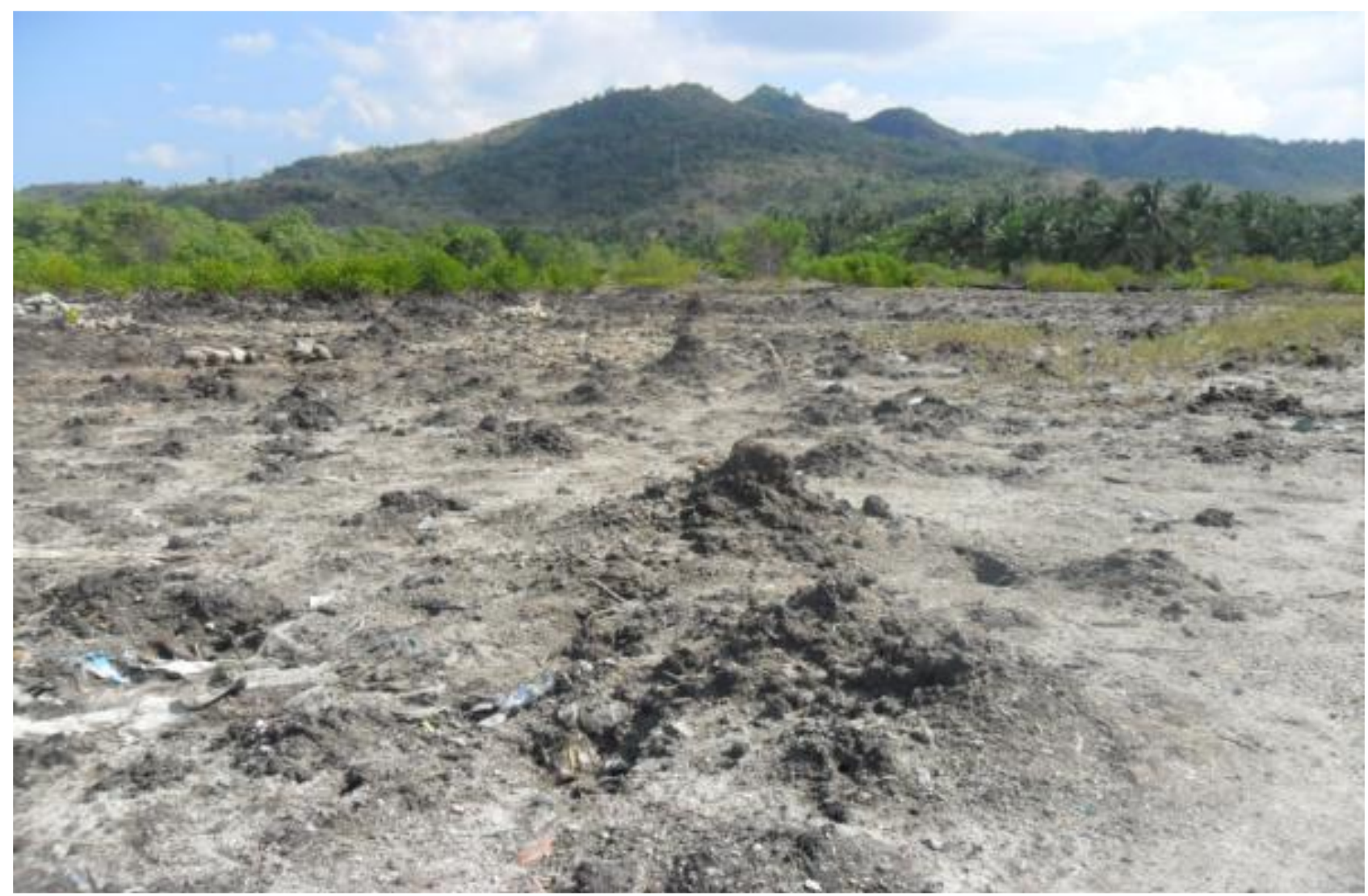

Gambar 12. Endapan hasil bentukan Rajungan callinectes sapidus

akan mati, kemudian hanya menyisahkan tempat tinggalnya berupa kumpulan karang. Proses yang terus berlangsung akan membentuk karang memanjang karena karang yang timbul. Karang yang timbul kepermukaan berupa teras-teras.Terumbu karang membentuk terumbu pinggiran kemudian berubah menjadi terumbu penghalang (Atmodjo, 2016). Gambar 11 menunjukkan bahawa kumpulan karang mati, disebabkan oleh sedimentasi. Diantara mangrove dan kumpulan karang terdapat endapan yang berlumpur bentuknya memanjang. Selain itu di sekitar mangrove banyak dijumpai gundukangundukan pasir yang merupakan hasil endapan pekerjaan organisme Rajungan callinectes sapidus.

Secara umum daerah endapan tidak terlalu nampak secara jelas (Gambar 12), persebaran endapan terdapat pada bagian utara lokasi penelitian yaitu di muara sungai Kalosi terdapat delta. Di Pattipur endapannya berupa pasir, dan kerikil, namun endapan tersebut hanya bisa kelihatan ketika air laut dalam keadaan surut. Di Passai endapannya berupa batu karang merupakan media berkumpulnya material-material dari sungai Passai, dengan endapan yang berlumpur di Passai ditemukan hutan mangrove. Selanjutnya di bagian selatan terdapat delta yang luas di muara sungai Teppo. Endapannya luas karena sungai Teppo merupakan sungai besar sehingga membawa banyak material dari daratan.

Endapan hasil organisme dapat ditemukan di Passai yaitu materialnya terdiri dari batuan yang berwarna putih dan bentuknya boulder yang gelombang tidak bisa mengakut dan mengumpulkannya. Menurut hasil wawancara batuan tersebut merupakan hasil sisa dari pembuatan tanggul buatan yang berada di pinggir jalan, sedangkan endapan yang berada di Tara Ujung merupakan hasil kerja binatang Rajungan callinectes sapidus membentuk gundukan-gundukan pasir.

\section{Kesimpulan}

Secara umum Pantai Rewata'a merupakan pantai yang terkikis atau terabrasi, walaupun terjadi pengendapan tetapi pengendapan tersebut sifatnya sementara. Material hasil kikisan lebih banyak diangkut masuk ke laut dibandingkan material yang dihempaskan ke daratan yang membentuk gisik. Berdasarkan klasifikasi penyusunnya pantai Rewata'a termasuk pantai berbatu yang tersusun oleh batuan induk yang keras seperti batuan beku atau sedimen yang keras. Walaupun dapat juga dijumpai dataran pasir di daerah Pattipur dan Teppo. Berdasarkan sudut pandang morfologinya pantai Rewata'a termasuk pantai bertebing (cliffed coast,) yaitu pantai yang memiliki tebing vertikal, selalu tergenangi air. 


\section{Referensi}

Arnott, \& Davidson, R. (2010). Introduction to Coastal Processes and Geomorphology. New York: Cambridge University Press. https://doi.org/10.1017/CBO9780511841507

Atmodjo, W. (2016). Geomorfologi Pesisir Pantai Benteng Portugis, Kecamatan Donorojo, Kabupaten Jepara. Jurnal Kelautan Tropis. 19(2), 150-160. https://doi.org/10.14710/jkt.v19i2.842

Bird, E. (2008). Coastal Geomorphology An Introduction, Second Edition. In John Wiley and Sons. https://doi.org/10.1007/s13398-014-0173-7.2

Craghan, M. (2003). Physical Geography : A Self-Teaching Guides. Canada: Wiley.

Dartoyo, A. (2004). Model Pengelolaan Wilayah Pesisir Kabupaten Berbasis Digital Studi Kasus : Kabupaten Cilacap Jawa Tengah. Indonesia: Disampaikan dalam Temu Alumni MPKD Bakosurtanal.

Dewandaru, D. P. \& Saputro, H. S. (2014). Kajian Morfologi Pantai di Pantai Slamaran Kabupaten Pekalongan. Journal Of Oceanography. 3(1), 105-123.

Eksan, D. H., Zainuri, A., \& Kasim, M. (2019). Potensi Batugamping Untuk Bahan Baku Industri Semen Daerah Biluhu Timur Dan Sekitarnya. Jambura Geoscience Review, 1(2), 68-76. https://doi.org/10.34312/jgeosrev.v1i2.2380.

Gunawan, T. \& Santosa, L.W. (2005). Pedoman Survei Cepat Terintegrasi Wilayah Kepesisira. Yogyakarta: BPFG.

Huda, A. C., Pratikto, I., \& Pribadi, R. (2019). Karakteristik Lahan terhadap Kerentanan Pesisir Pantai Kabupaten Rembang, Jawa Tengah. Jurnal of Marine research. 8(3), 253-261.

Marfai, M. A., Sekaranom, A. B., \& Ward, P. (2015). Community responses and adaptation strategies toward flood hazard in Jakarta, Indonesia. Natural Hazards. https://doi.org/10.1007/s11069-0141365-3.

Mulyanto, H.R. (2010). Prinsip Rekayasa Pengendalian dan Pantai. Graha Ilmu: Yogyakarta.

Munir, M. (2003). Geologi Lingkungan. Malang: Bayumedia Publishing.

Noor, Djauhari. (2011).Geologi untuk Perencanaan. Bogor: Graha Ilmu

Nofirman. (2017). Perubahan Morfologi Pantai Dengan Integrasi Citra Di Wilayah Kabupaten Bengkulu Utar. Journal Georaflesia. 2(2).

Nuriyanto et al. (2018). Analisis Perubahan Bentang Geomorfologi Pantai Bentar Kabupaten Probolingg. Program Studi Pendidikan Geografi, Universitas Jember, Indonesia

Rusdi, \& Marfai, M.A. (2014). Persepsi dan Adaptasi Masyarakat Dalam Pengurangan Risiko Dampak Erosi Pantai Di Kabupaten Pinrang Sulawesi Selatan. Tesis. Yogyakarta: Universitas Gadjah Mada

Sampurno, Dott. (2007) Pengembangan Kawasan Pantai Kaitannya dengan Geomorfologi. Departemen Geologi ITB.

Sarbidi. (2007). Geomorfologi dan Wilayah Pantai Kota Semarang. Pusat Penelitian dan Pengembangan Pemukiman.

Solihuddin, T.B. (2011). Karakteristik Pantai Dan Proses Abrasi Di Pesisir Padang Pariaman, Sumatera Barat. Globë. 13(2), 112 - 120.

Shofian et al. (2019). Geomorfologi Perairan Muara Sungai Kaliboyo Batang Jawa Tengah. Journal of Marine Research. 8(4), 431-438.

Tika, Pabundu. (2005). Metode Penelitian Geografi. Jakarta: PT Bumi Aksara. 